Trinity University

Digital Commons @ Trinity

School of Business Faculty Research

School of Business

4-1999

\title{
The Importance of Call Delays and Cash Flow Positions in Evaluating the Information Content of Convertible Preferred Stock Calls
}

\author{
L. Paige Fields
}

Michael S. Wilkins

Trinity University, mike.wilkins@trinity.edu

Eric L. Mais

Follow this and additional works at: https://digitalcommons.trinity.edu/busadmin_faculty

Part of the Business Commons

\section{Repository Citation}

Fields, L.P., Wilkins, M.S., \& Mais, E.L. (1999). The importance of call delays and cash flow positions in evaluating the information content of convertible preferred stock calls. Journal of Accounting, Auditing, \& Finance, 14(2), 163-183. doi: 10.1177/ $0148558 X 9901400204$ 


\title{
The Importance of Call Delays and Cash Flow Positions in Evaluating the Information Content of Convertible Preferred Stock Calls
}

\author{
L. PAige Fields* \\ MiChAEL S. WILKINS** \\ ERIC L. MAIS***
}

\begin{abstract}
We examine a sample of in-the-money convertible preferred stock calls and find that they are delayed. We find that the length of the call delay does not depend on the relation between the preferred stock dividends and the pro rata common dividends to be paid on conversion. Thus, our evidence suggests that preferred stock calls may be used for signaling purposes. In support of this, we find that only delayed calls (i.e., those with potential signaling elements) are viewed negatively by equity investors. We also show that, in responding to delayed call announcements, investors appear to react to two distinct information elements. First, price responses to delayed calls are increasingly negative the larger the cash flow disadvantage to calling. In other words, common investors respond more negatively to calls when the forced conversion results in convertible holders receiving larger dividends than were previously required. Second, both cash flow advantage and cash flow disadvantage firms experience significant downward shifts in earnings growth during post-call periods, suggesting that delayed calls are timely signals of decreasing profitability.
\end{abstract}

\section{Introduction}

Academic researchers have devoted considerable time to the study of convertible security calls. Given the theoretical proposition that a security should be called as soon as its conversion value exceeds its call price (Brennan and Schwartz [1977]; Ingersoll [1977a]), and some empirical findings to the contrary, much of

*College of Business Administration Department of Finance, Texas A\&M University

**College of Business Administration, Department of Accounting. Texas A\&M University

***College of Business Administration, University of Hawaii

The authors would like to thank Christine Collins and Lori Holder-Webb for research assistance and Alan Montgomery for computer support. 
the literature focuses on whether calls of convertible securities are delayed. ${ }^{1}$ Several studies (e.g., Ingersoll [1977b], Constantinides and Grundy [1987]) find that convertible securities are deep in-the-money when called, and thus conclude that calls are delayed. Other studies (e.g., Asquith [1995]; Dunn and Eades [1989]) examine the appropriateness of call timing based on whether call protection periods have lapsed, whether positive option premia exist, and/or whether firms have consistent relative cash flow positions when call decisions are made.

Another segment of the literature examines stock price reactions and firm performance surrounding convertible security calls. The purpose of these studies (e.g., Byrd and Moore [1996]; Shastri and Shastri [1996]; Campbell, Ederington, and Vankudre [1991]) is to determine whether calls convey information to the market. Although such studies typically conclude that no material earnings-based signals are sent, at least one critical oversight persists - tests for information effects invariably are conducted without properly accounting for whether the underlying calls are delayed.

Most of these studies focus on in-the-money securities, implicitly assuming that the associated calls are delayed. ${ }^{2}$ However, Asquith's (1995) analysis of convertible bonds shows that securities may be in-the-money at the time of the call without their calls being delayed. In other words, although "in-the-moneyness"' is doubtless a necessary condition for the existence of a call delay, it is not a sufficient condition. For example, calls may be made immediately after call protection periods expire or when the security's option premium is negative. Under either of these scenarios, even if the securities are in-the-money at the time of the call, the calls are not "delayed." As a result, no information effects should exist. In essence, treating delayed and nondelayed calls as equal both ignores the theoretical underpinnings of optimal call policy and biases against detecting information effects in empirical tests.

Asquith (1995) illustrates that convertible bond calls are not delayed; therefore, it is unlikely that convertible bond calls have signaling elements. However, Dunn and Eades (1989) and Byrd et. al (1997) report conflicting evidence regarding convertible preferred stock call delays. ${ }^{3}$ Given this discrepancy, the first question that this paper addresses is whether convertible preferred stock calls are delayed.

1. In order for the call to transfer the option value from convertible preferred stockholders to common stockholders, the preferred security's market price must exceed its conversion value.

2. Out-of-the-money calls (i.e., "early calls") are much less frequent and are not directly comparable to in-the-money calls. Acharya and Handa (1991) report that only about 20 percent of convertible bond calls are out-of-the-money.

3. Call delays may exist for convertible preferred stock issues and not for convertible bond issues due to tax shield and maturity differences. Mikkelson (1985) suggests that firms call convertible debt due to the anticipated loss of future debt tax shields. This may prompt firms to call convertible bonds for reasons that would not result in a call of convertible preferred securities. Additionally, the finite life of convertible bonds gives rise to a shorter window of opportunity, during which a call would allow for expropriation of wealth from bondholders to shareholders. Either of these factors might account for the shorter (or zero) cross-sectional call delay for convertible bonds, as identified by Asquith (1995). 
We then investigate whether existing delays are consistent with the cash flow arguments presented by Asquith and Mullins (1991), and whether delayed calls contain elements of information signaling.

Our tests show that convertible preferred stock calls are delayed. ${ }^{4}$ The 71 firms in our sample delay calling by an average of more than three months after allowing for a 20 percent safety margin and after considering call protection periods. We also show, in contrast to Asquith (1995), that call delay length cannot be explained by firms' relative cash flow positions. This finding reintroduces the possibility that delayed convertible preferred stock calls may convey information. In support of this proposition, we show that the announcement period price effect is significantly negative only for the subsample of firms that delay calling, and is most negative for firms that force conversion when there is a cash flow disadvantage to doing so. Our final tests illustrate that delayed calls are followed by significant decreases in earnings growth. In total, our results indicate that by failing to analyze only delayed calls, previous studies may have missed an important factor in evaluating the information content of convertible preferred stock calls.

The remainder of the paper is organized as follows. Section 2 provides a brief review of the empirical literature regarding convertible security calls. Section 3 describes our sample selection procedure and sample summary characteristics, and Section 4 provides an analysis of call delays. Section 5 presents the results of our event study, and Section 6 presents the cross-sectional regression analysis. The approach used to measure earnings growth changes around the call announcements and the results of the analysis are described in Section 7. Section 8 presents alternative specifications and sensitivity tests, and the final section provides a summary and concluding remarks.

\section{Literature Review}

\subsection{Cash Flow Positions and Stock Price Effects}

Ingersoll (1977a) shows that convertible securities should be called as soon as the conversion value exceeds the call price. However, Ingersoll (1977b) documents that the median firm waits until the conversion value exceeds the call price by 44 percent. To explain this apparent anomaly, Constantinides and Grundy (1987) and Asquith and Mullins (1991) posit that the timing of a call may depend on firms' cash flow positions and, as a result, may be critical in determining whether the call has information value. Specifically, they suggest that a firm's call decision may be a function of the relation between the existing required payments on the convertible securities and the common dividends that would be paid if the securities were

4. As with most other studies examining convertible preferred stock calls, all of our convertible preferred issues have conversion values that are greater than their call prices. However, the calls we examine are truly delayed in that (1) the 20 percent safety premium is incorporated, (2) call protection periods have expired. and (3) 88 percent of the issues have market prices that are greater than their conversion values (i.e., have positive option premia). 
converted. For example, firms having preferred dividend payments that are higher than their pro rata common dividend payments (cash flow advantage firms) may be expected to call as quickly as possible because there is a cash flow advantage to doing so. On the other hand, firms having common dividend payments that are higher than the required preferred dividend payments (cash flow disadvantage firms) may be expected to delay calling to conserve cash.

Jaffe and Shleifer (1990) argue that to ensure that the convertible security is still in-the-money when the call is completed, firms in a cash flow advantage position may rationally delay a call until the conversion value exceeds the call price by a certain safety margin. Brigham's (1966) survey of managers reports that managers consider a 20 percent premium a sufficient safety margin. Asquith and Mullins (1991) propose the same 20 percent safety premium, stating that this figure is commonly used by both managers and investment bankers. Asquith and Mullins (1991) also report that the 20 percent premium is almost twice the average monthly standard deviation of stock returns for their sample, suggesting that it is a reasonable empirical proxy for the safety margin described by Jaffe and Shleifer (1990).

\subsection{Signaling and Stock Price Effects}

Although cash flow advantage and disadvantage positions may explain part of firms' call decisions, signaling elements may exist as well. Harris and Raviv (1985) present a formal model of convertible bond call policy with asymmetric information between managers and investors. They show that call delays signal managers' expectations that common stock prices will rise in the future, causing convertible security holders to convert voluntarily. In contrast, managers choose to call in-themoney securities when they expect that future common stock prices will not be high enough to entice voluntary conversion. Therefore, the decision to call may signal managers' private expectations regarding (decreasing) future cash flows. ${ }^{5}$ Comparable directional predictions are generated by Constantinides and Grundy (1987), who suggest that a call forcing conversion may convey the expectation that common dividends will not rise sufficiently in the future to invoke voluntary conversion. In support of these signaling hypotheses, empirical studies by Mikkelson (1981) and Mais, Moore, and Rogers (1989) document negative abnormal returns to common stock in response to announcements of convertible bond and convertible preferred stock calls, respectively.

Asquith (1995) analyzes deviations from optimal call policy for in-the-money convertible bonds. ${ }^{6}$ Asquith (1995) measures call delay as the number of days convertible bonds remain uncalled when they are 120 percent in-the-money and

5. The signaling model of Harris and Raviv (1985) applies most directly to convertible bonds in that the model incorporates the finite life of the bonds' conversion option. Because most convertible preferreds entail perpetual options, this model would have to be expanded to generate identical predictions for preferred calls.

6. Optimal call policy also requires that the price of the convertible security exceed its conversion value in order for the call to squelch the option value of the security. 
call protection periods have expired. ${ }^{7} \mathrm{He}$ finds that no significant call delay exists beyond that which can be rationalized by call protection periods and cash flow disadvantage positions. He therefore concludes that convertible bond calls are not used to signal managers' views regarding future cash flows.

Byrd et al. (1997) find that calls of convertible preferred stock are delayed when delay is defined, as in Asquith (1995), as the number of days an in-themoney convertible preferred issue remains uncalled after the protection period has passed. They also find that the delay cannot be explained by firms' cash flow positions. However, for 17 of their 23 called in-the-money issues, they find that the average option premium is negative, implying that the opportunity for a wealth transfer from preferred shareholders to common shareholders prior to the call did not exist. Dunn and Eades (1989), however, find a positive average option premium for their sample of 57 conversion-forcing preferred stock calls; thus, the evidence regarding option premia is mixed. ${ }^{8}$

A few recent studies have examined the valuation effects of calls of out-ofthe-money convertible securities. In contrast to the negative signaling implications associated with in-the-money calls, managers may choose to call out-of-the-money convertible securities if they believe their firm is undervalued. By eliminating the conversion opportunity, managers force the convertible security holders to accept a fixed claim that is equal to the call price, thereby preventing them from sharing in any residual claim that is gained when the market realizes the firm's true value. The empirical studies of such "early" calls (e.g., Tang, Kadapakkam, and Singer [1994], Hingorani, Makhija, and Shastri [1994]; Cowan, Nayar, and Singh [1993]) find positive abnormal returns to common stock when the calls are announced, suggesting that such calls signal managers' private expectations of higher future cash flows. These studies are not directly comparable to ours, given that "early" calls, by definition, are not delayed and do not serve as negative signals regarding future profitability.

\subsection{Calls of Convertible Securities and Changes in Firm Performance}

Harris and Raviv (1985) show that managers choose to call in-the-money securities when future common stock prices are not expected to be high enough to entice voluntary conversion. In support of this contention, Ofer and Natarajan (1987) find that in-the-money convertible bond calls are associated with decreased post-call earnings. However, Campbell, Ederington, and Vankudre (1991), hereafter $\mathrm{CEV}$, argue that the negative post-call abnormal returns and earnings changes docu-

7. Asquith uses the number of consecutive days the bonds remain uncalled (and other measures) and draws identical conclusions.

8. Dunn and Eades (1989) find that firms do violate optimal call policy by delaying calls of convertible preferred stock. However, they conclude that the strategy used by firms resulting from suboptimal conversion on the part of investors is not inferior to the Ingersoll (1977a) and Brennan and Schwartz (1977) models of optimal call policy. 
mented by Ofer and Natarajan (1987) may be biased due to the parameter estimation periods used in their study. ${ }^{9} \mathrm{CEV}$ find insignificant post-call cumulative abnormal returns when sized-based return portfolios or post-period parameter estimations are used. Additionally, they find that earnings changes and abnormal stock price performance depend on the relationship between the after-tax interest payments made to convertible bondholders and the common dividend they would receive if conversion were forced by the call.

Byrd and Moore (1996) examine Value Line earnings forecast revisions made after firms called convertible securities. Their analysis of 90 firms calling convertible bonds and 36 firms calling convertible preferred stock reveals that analysts' earnings forecasts are revised upward following call announcements. In addition, Byrd and Moore (1996) present evidence that the raw price effect for convertible call announcements may be transitory. Shastri and Shastri (1996) also examine analysts' earnings forecast revisions following conversion-forcing calls of convertible preferred stock. They find that analysts' forecasts are not revised significantly, but that the variance of analysts' forecasts decreases after calls are announced. Shastri and Shastri (1996) also document a significant increase in earnings per share during the call year. These results, as well as Asquith's (1995) finding of little or no delay for calls of convertible bonds, run counter to signaling models that treat calls as being indicative of decreased expected future cash flows.

\subsection{Contribution of the Present Research}

A large body of theoretical and empirical work addresses calls of convertible securities. Empirical studies typically attempt to determine whether call delays exist or investigate various aspects of firm performance surrounding call announcements. Thus far, however, no study has combined the two lines of inquiry to present a cohesive picture of the call decision. As a result, many of the relevant questions have not yet been answered satisfactorily. Because Asquith's (1995) work casts serious doubt on the value of further considering the question of convertible bond call timing and information, this study focuses on convertible preferred stock calls. In the following sections, we investigate the nature of call delays and provide evidence that delayed calls contain elements of information signaling.

\section{Sample Selection and Summary Statistics}

Our initial sample of convertible preferred stock calls was identified by examining yearly changes in preferred stock and convertible preferred stock, as reported on Compustat between 1962 and 1992. We then searched both the Wall Street Journal and LEXIS/NEXIS for publicly announced calls of convertible pre-

9. Cowan, Nayar, and Singh (1992) also show that postperiod estimation is most appropriate in assessing postcall performance. 
TABLE 1

\section{Basic Summary Statistics for Calls of In-the-Money Convertible Preferred Stock Issues Occurring between 1963 and 1992}

\begin{tabular}{|c|c|c|c|}
\hline Descriptive Measure & $\mathbf{N}$ & Mean & Median \\
\hline \multicolumn{4}{|l|}{ Call size (millions)" } \\
\hline Complete sample & 68 & $\$ 40.460$ & $\$ 21.785$ \\
\hline Cash flow advantage & 55 & $\$ 44.319$ & $\$ 22.000$ \\
\hline Cash flow disadvantage & 13 & $\$ 24.125$ & $\$ 9.400$ \\
\hline \multicolumn{4}{|c|}{ Conversion value to call price ${ }^{\mathrm{h}}$} \\
\hline Complete sample & 71 & 1.673 & 1.390 \\
\hline Cash flow advantage & 57 & 1.700 & 1.392 \\
\hline Cash flow disadvantage & 14 & 1.575 & 1.279 \\
\hline \multicolumn{4}{|c|}{ Percentage of original issue called } \\
\hline Complete sample & 39 & 68.885 & 82.080 \\
\hline Cash flow advantage & 31 & 76.381 & 88.210 \\
\hline Cash flow disadvantage & 8 & 39.839 & 28.690 \\
\hline \multicolumn{4}{|l|}{ Cash flow position (millions) } \\
\hline Complete sample & 68 & $\$ 1.567$ & $\$ 0.379$ \\
\hline Cash flow advantage & 55 & $\$ 1.962$ & $\$ 0.713$ \\
\hline Cash flow disadvantage & 13 & $\$-0.109$ & $\$-0.033$ \\
\hline
\end{tabular}

Cash flow advantage (disadvantage) refers to a firm paying annual pro rata common dividends that are lower (higher) than the annual dividends required on the convertible preferred shares.

"Call size is the total number of preferred shares called multiplied by the call price. The total number of shares called could not be determined for 12 of the sample firms.

'Conversion value is measured as of the call announcement date.

'Cash flow position is the total annual convertible preferred dividends minus the total annual pro rata common dividends.

ferred stock. ${ }^{10}$ For the earnings growth analysis, complete earnings data must be available from Compustat, annual reports, or Moody's manuals from at least three years before to three years after the call year (year 0 ). These screens resulted in a sample of 71 calls that were used in the earnings analysis. For the event study analysis, daily common stock returns must be available from either the security issuance date or the end of the call protection period (when call protection exists) to 400 days after the call announcement date. Sixty-seven observations survived the returns screen.

Table 1 presents selected summary statistics for our sample of firms. The median dollar size of the called issues is $\$ 21.785$ million for the complete sample. The median size of the called issues for the cash flow advantage subsample is more than twice that of the cash flow disadvantage subsample. Constantinides and

10. Duplicate firms and out-of-the-money calls were excluded from the initial sample. The remaining call announcements are distributed fairly evenly across the sample years. There appears to be little clustering of events. None of the calls was made in conjunction with a merger or an acquisition. 
Grundy (1987) suggest that a firm may call an in-the-money convertible issue when it is in a cash flow disadvantage position to eliminate servicing costs for the relatively few remaining unconverted securities. The smaller aggregate call size for disadvantage firms, coupled with the fact that the median call represents 28.6 percent of the original issue (compared to $88.2 \%$ for advantage firms), may be consistent with disadvantage firms using calls as "cleanup" operations.

The called issues are deep in-the-money, with a median conversion value to call price ratio of 1.390 . The cash flow advantage subsample is deeper in-the-money than the cash flow disadvantage subsample, with a conversion value to call price ratio of 1.392 (compared to 1.279). For the cash flow disadvantage group, total preferred dividends are less than total common dividends by an average of $\$ 0.109$ million. For the cash flow advantage group, preferred dividends exceed common dividends by an average of $\$ 1.962$ million. ${ }^{11}$

\section{The Existence and Nature of Call Delays}

\subsection{Call Delay Measures}

Table 2 provides summary information regarding the median, upper quartile, and lower quartile call delays for our sample of 71 firms. Like Asquith (1995), we initially measured "call delay" by summing the number of days that the conversion value exceeded the call price ( $\mathrm{CV}>\mathrm{CP}$ ) between either (1) the issue date or (2) the end of the call protection period and the call announcement date. ${ }^{12}$ Conversion values were calculated for each trading day by multiplying the firm's common stock price by its conversion ratio. To ensure consistency, the conversion ratios were adjusted for all stock splits and stock dividends occurring between the issue date and the call announcement date. For 13 of the 71 firms, the issue was called immediately after call protection expired or when the call was first in-the-money. For these 13 firms there is zero call delay. The median call delay for the complete sample, including firms with zero call delay, is 177 trading days; that is, our sample firms announced calls of their convertible preferred stock issues in excess of eight months, on average, after they were first in-the-money (and call protection had ended). ${ }^{13}$

Asquith and Mullins (1991) and Brigham (1966) suggest that firms typically make the decision to call (in the spirit of Jaffe and Shleifer [1990]) after the issue is 120 percent in-the-money to ensure that the security is still in-the-money when

11. The mean cash flow advantage (disadvantage) of $\$ 1.962$ million ( $\$-0.109$ million) represents 0.41 percent $(0.05 \%)$ of total market value of equity.

12. Thirty-one of the issues were call protected. For the issues with call protection, the period of protection generally lasted five years. For six firms, the call delay will be understated because CRSP returns data are first available beginning in 1962. For example, securities issued prior to 1962 that are in-the-money as of the first day of available CRSP data likely had been in-the-money much longer than is revealed in our analysis. The only effect, however, is to bias against finding a call delay.

13. This 177-day period does not include the call period, which is typically an additional 30 days for our sample. 
TABLE 2

\section{Summary Statistics Regarding the Number of Days Firms Delay Calling Convertible Preferred Stock Issues}

\begin{tabular}{|c|c|c|c|}
\hline Sample & $\begin{array}{c}\text { Upper } \\
\text { Quartile }\end{array}$ & Median & $\begin{array}{l}\text { Lower } \\
\text { Quartile }\end{array}$ \\
\hline
\end{tabular}

Panel A. Complete sample $(N=71)$

Number of days $120 \%$ in-the-money

Number of consecutive days in-the-money

once the issue is $120 \%$ in-the-money

\begin{tabular}{rrr}
313 & 177 & 70 \\
126 & 67 & 10 \\
112 & 62 & 11 \\
\hline
\end{tabular}

Panel $B$. Firms with cash flow advantage to calling $(N=57)^{a}$

\begin{tabular}{|c|c|c|c|}
\hline Number of days in-the-money & 251 & 168 & 56 \\
\hline Number of days $120 \%$ in-the-money & 125 & 67 & 10 \\
\hline Number of consecutive days in-the-money & & & \\
\hline once the issue is $120 \%$ in-the-money & 112 & 60 & 11 \\
\hline
\end{tabular}

Panel C. Firms with cash flow disadvantage to calling $(N=14)^{\mathrm{b}}$

Number of days in-the-money

Number of days $120 \%$ in-the-money

Number of consecutive days in-the-money,

once the issue is $120 \%$ in-the-money

$\begin{array}{rrr}420 & 253 & 169 \\ 145 & 68 & 7 \\ 102 & 84 & 0\end{array}$

Note that median and upper and lower quartile values are presented here for the complete sample and for subsamples partitioned according to cash flow position.

"Cash flow advantage firms are firms with preferred dividends greater than pro rata common dividends.

"Cash flow disadvantage firms are firms with pro rata common dividends greater than or equal to preferred dividends.

the call is completed. Therefore, the optimal call date can be viewed as the date on which the firm's common stock price exceeds the call price by 20 percent. When we introduce this 20 percent safety margin, we find that a material delay still exists. The median interval in which the issues are 120 percent in-the-money is 67 trading days. In other words, even if the optimal call date is redefined to allow for the 20 percent premium, we find that firms still delay calling their convertible preferred stock in excess of three months, in addition to the typical 30- to 60-day call period.

For some firms, beginning measurement of the delay on the first day the securities are in-the-money (or $120 \%$ in-the-money) may not provide the best indication of the deviation from optimal call policy. Some issues, for example, may fall out-of-the-money rather quickly and may not be in-the-money again until a later date. Therefore, we implement an alternative measure that is based on the number of consecutive days the security is in-the-money after it initially satisfies 
the 20 percent call safety margin. We find that for over 75 percent of our sample firms, the securities do not fall out-of-the-money once the 20 percent safety margin is reached. Across all firms, the median number of consecutive pre-announcement days the issues are in-the-money, beyond the 20 percent safety margin, is 62 days (see Table 2). The evidence from panel A indicates, therefore, that call delays persist across all specifications.

\subsection{Call Delays and Cash Flow Positions}

Asquith (1995) finds, for a sample of convertible bond calls, that firms that are in a cash flow advantage position have a much shorter call delay than do firms that are in a cash flow disadvantage position. For our sample of convertible preferred stock calls, however, the average call delay length does not appear to depend on firms' cash flow positions. Panel B of Table 2 shows that firms in a cash flow advantage position have a median call delay, after factoring in the 20 percent safety premium, of 67 days. This interval is virtually identical to that of firms in a cash flow disadvantage position ( 68 days). However, the median number of consecutive days in-the-money once the 20 percent safety margin is reached is somewhat shorter for cash flow advantage firms (60 days) than for cash flow disadvantage firms (84 days).

To provide a more formal test of the relation between call delays and cash flow positions, we estimate the following model from Asquith (1995). The purpose of the model is to determine whether the relation between the common dividend and the preferred dividend adjusted for the conversion ratio explains the length of call delays experienced by our sample firms.

$$
\operatorname{DELAY}_{j}=\alpha+\beta \operatorname{DIVRAT}_{j}+\varepsilon_{j}
$$

In eq. (1), all variables are as defined by Asquith (1995). Specifically, DELAY is the $\log$ of the number of days the security was 120 percent in-the-money and DIVRAT is the $\log$ of the ratio of the largest annualized common dividend paid from the time the security was first 120 percent in-the-money until it was called to the annual dividend paid to the preferred holders (adjusted for the conversion ratio). ${ }^{14}$ Asquith (1995) finds $\beta$ to be positive and significant for his sample of convertible bond calls and concludes that call delays are an increasing function of the cash flow disadvantage to calling. By extension and with additional analysis, Asquith concludes that convertible bond calls are not delayed irrationally. Our finding for convertible preferred stock calls, however, is that $\beta$, while positive, is

14. One issue was called prior to being 120 percent in-the-money. In the regression analysis the call delay used for this firm is the number of days the issue was in-the-money. The information in Table 2 reflects zero days at 120 percent in-the-money for this sample point. 
not significant. ${ }^{15}$ We conclude that the relative size of the preferred and common dividends may influence the decision to call convertible preferred stock, but that it does not explain the length of the call delay that we detect. In other words, Asquith's findings for convertible bond calls do not appear to hold for calls of convertible preferred stock.

\subsection{Sensitivity Tests-Option Premia}

To complete the call delay analysis, we investigated the option premia associated with the called issues. Specifically, we calculated the option premium, defined as the preferred stock's market price minus its conversion value, for each firm for every trading day in which conversion could have been forced (i.e., when the security was in-the-money and the protection period had passed). ${ }^{16}$ In this framework, the existence of a positive average premium across the period would suggest that the call, which would expropriate the option premium to the benefit of common shareholders, was delayed. Unlike Byrd et. al (1997) who find that only 26 percent ( 6 of 23 ) of the conversion-forcing calls in their sample have a positive average option premium, we find that 88 percent of our calls have a positive premium. ${ }^{17}$ Under an alternative specification that defines the premium as the ratio of the preferred price to the conversion value, our mean option premium is 1.021 . This value is very similar to the 1.029 mean option premium noted by Dunn and Eades (1989). ${ }^{18}$

Based on these findings and on the results presented in previous sections, our conclusion is that convertible preferred stock calls are delayed. Our results hold after considering call protection periods and are robust to numerous alternative specifications. Furthermore, unlike convertible bond calls, the delay associated with calls of convertible preferred stock cannot be explained by firms' cash flow positions.

15. Variables including the dollar value of the called issue, a dummy variable representing whether the call was underwritten, and the average option premium over the delay period were also included in eq. (1). None of the coefficient estimates were statistically significant. The results are qualitatively unchanged when DELAY is defined as the number of consecutive days the securities are in-the-money prior to the call announcement beginning with the first day the securities are 120 percent in-the-money. The results are even less significant $(p=0.84)$ when the raw rather than the logged values are used in the model. We emphasize the results for the model using the logged specification so that they are directly comparable to Asquith (1995).

16. For our sample of 58 firms with calls that were not called immediately once they were inthe-money or after call protection expired, 42 had complete preferred stock price data available for calculating the average option premium.

17. It is possible, but doubtful, that the difference in our findings and those of Byrd et al. (1997) is due to the fact that only 14 of their 23 calls were publicly announced. Of the 14 publicly announced calls studied by Byrd et al. (1997) we do not know how many have positive option premium values, nor do we know the average option premium they find for all 23 conversion-forcing calls.

18. If the firm conforms to optimal call policy, transaction costs are zero, and there is no call period, the expected value under the null hypothesis of the difference between the convertible preferred price and the conversion value is zero. Under the same conditions the expected value of the ratio of the convertible preferred price to the conversion value is one. 
TABLE 3

Event Study Results for Firms Announcing Calls of Convertible Preferred Stock

\begin{tabular}{|c|c|c|c|c|}
\hline \multicolumn{5}{|c|}{ Panel $A$. Firms that delay calling $(N=56)$} \\
\hline \multirow[b]{2}{*}{ Interval } & \multicolumn{2}{|c|}{ Preperiod Estimation (\%) } & \multicolumn{2}{|c|}{ Postperiod Estimation (\%) } \\
\hline & Mean CAR & Median CAR & Mean CAR & Median CAR \\
\hline$(-100,-2)$ & $7.95 * *$ & $7.34 * *$ & $17.97 * *$ & $14.75 * *$ \\
\hline$(-1,0)$ & $-1.97 * *$ & $-1.57 * *$ & $-1.70^{* *}$ & $-1.48 * *$ \\
\hline$(+1,+100)$ & $-10.87^{* *}$ & -10.89 & -0.44 & -3.43 \\
\hline
\end{tabular}

Panel $B$. Firms that do not delay calling $(N=11)$

\begin{tabular}{lccccc} 
& \multicolumn{2}{c}{ Preperiod Estimation (\%) } & & \multicolumn{2}{c}{ Postperiod Estimation (\%) } \\
\cline { 2 - 3 } Interval & Mean CAR & Median CAR & & Mean CAR & Median CAR \\
\hline$(-100,-2)$ & 7.24 & 0.68 & & 7.95 & 11.42 \\
$(-1,0)$ & -0.63 & -1.05 & & -0.70 & -0.75 \\
$(+1,+100)$ & 0.99 & -2.81 & & 1.90 & 1.50
\end{tabular}

** Denotes significance at $p \leq 0.05$

\section{Abnormal Returns to Common Stock}

We use an event study method to measure the common stock price response to announcements of delayed calls of convertible preferred stock. Abnormal returns are calculated for the period beginning 200 days before to 200 days after the call announcement date using a value-weighted market model. ${ }^{19}$ For the pre-event estimation procedure, the estimated coefficients are calculated using the 200 trading days that end 201 days prior to the announcement date. For the post-event estimation procedure, the coefficients are estimated using the 200 trading days beginning 201 days after the announcement date. Tests of statistical significance are based on $Z$ statistics calculated using the method of Mikkelson and Partch (1988). Wilcoxon rank-sum tests are used to evaluate the significance of median abnormal returns.

Table 3 presents the event study results for the nondelayed calls and for the delayed calls. We find that only delayed calls are associated with significantly decreased common shareholder wealth at announcement. Specifically, using the post-event estimation procedure, we detect a mean abnormal share price response

19. Our results do not differ qualitatively when an equally weighted market model is estimated, nor when we estimate betas in the manner of Scholes and Williams (1977). The market index that is used in our market model estimations is a combined NYSE/AMEX and NASDAQ index. Seven of the sample firms are traded on AMEX and two are traded on NASDAQ. Share price responses do not differ significantly across exchanges. 
of -1.70 percent $(p<0.01)$ for firms that delayed calling. The median abnormal share price response of -1.48 percent is also significant at the 0.01 level. These results contrast our finding of an insignificant two-day abnormal return for the zerodelay firms. We also find that the announcement period abnormal returns for the delayed call sample are significantly different from (i.e., are more negative than) those of the nondelayed sample $(p<0.04)$. In other words, only delayed callsthat is, those that may be expected to have information content-result in significant share price depreciation. ${ }^{20}$

The results presented in Table 3 suggest that announcement period stock price performance is independent of the parameter estimation period that is employed. However, consistent with CEV, we find that the post-call abnormal returns calculated from post-event estimation parameters are not significantly different from zero. $^{21}$ Therefore, our results based on the post-event parameter estimation for the delayed call sample of firms suggest that negative information may be revealed at the announcement of these calls, and that the announcement period effect may not be transitory. This conclusion is consistent with the finding of Mazzeo and Moore (1992) that announcement period abnormal returns for calls of convertible preferred stock are not correlated with cumulative abnormal returns over the conversion period.

\section{Cross-Sectional Analysis}

In this section, we present an analysis of the cross-sectional determinants of price responses to delayed call announcements. Our analysis is similar to that of Kadapakkam and Tang (1996), Hingorani et al. (1994), and Cowan, Nayar, and Singh (1992). An important difference, however, is that our tests include only delayed calls. From a theoretical perspective, and as was documented empirically in the previous section, these are the only types of calls that should have information content.

Table 4 presents the results of our cross-sectional analysis. In all models the dependent variable is the two-day abnormal return. Independent variables include UNDER, which is equal to one if the call was underwritten and zero otherwise; RELSIZE, which represents the size of the call relative to the firm's market value of common equity; DIVRAT (defined as in eq. [1]), which measures the magnitude of the cash flow advantage or disadvantage to calling; and EXTENT, which measures the degree to which the convertible preferred issue was in-the-money when it was called.

The first variable to be included (model 1) is UNDER. Cowan, Nayar, and

20. When the delay subsample is defined as firms also having positive option premia, the sample size is reduced to 37 . The two-day abnormal return for this subsample is $-1.92 \%(Z=-3.69)$.

21. Our finding of significantly positive pre-period abnormal returns and insignificant post-period abnormal returns is comparable to the results presented in CEV's study of convertible bond calls. Given the potential bias resulting from the use of pre-event parameter estimation techniques (see CEV for a description of this problem) the post-event results are deemed more reliable. 
TABLE 4

Results of Selected Cross-Sectional Regressions for the Sample of Firms with Delayed Calls of Convertible Preferred Stock (Test Statistics Are in Parentheses)

\begin{tabular}{|c|c|c|c|c|c|c|}
\hline & CONSTANT & UNDER & RELSIZE & DIVRAT & EXTENT & Adjusted $\mathrm{R}^{2}$ \\
\hline \multirow[t]{2}{*}{ Model 1} & $-0.90^{* *}$ & $-1.78^{* *}$ & - & - & - & \\
\hline & $(-2.38)$ & $(-2.48)$ & & & & 0.095 \\
\hline \multirow[t]{2}{*}{ Model 2} & $-0.87^{*}$ & $-1.76^{* *}$ & -0.44 & - & - & \\
\hline & $(-1.71)$ & $(-2.35)$ & $(-0.08)$ & & & 0.076 \\
\hline \multirow[t]{2}{*}{ Model 3} & $-1.12 * *$ & $-2.02 * *$ & -1.59 & $-2.84 * *$ & - & \\
\hline & $(-2.20)$ & $(-2.74)$ & $(-0.32)$ & $(-2.04)$ & & 0.135 \\
\hline \multirow[t]{2}{*}{ Model 4} & $-1.08^{*}$ & $-2.04 * *$ & -1.75 & $-2.85^{* *}$ & -0.03 & \\
\hline & $(-1.90)$ & $(-2.72)$ & $(-0.35)$ & $(-2.02)$ & $(-0.17)$ & 0.115 \\
\hline \multicolumn{7}{|c|}{ *Denotes significance at $p \leq 0.10$} \\
\hline \multicolumn{7}{|c|}{ ** Denotes significance at $p \leq 0.05$} \\
\hline \multicolumn{7}{|c|}{ UNDER $=1$ if the call was undewritten, 0 otherwise. } \\
\hline \multicolumn{7}{|c|}{ RESIZE = aggregate call price/market value of common equity. } \\
\hline \multicolumn{7}{|c|}{ DIVRAT $=\log$ of (common dividend/preferred dividend adjusted for conversion ratio), as per } \\
\hline
\end{tabular}

Singh (1992) suggest that managers are likely to enlist the services of an underwriter if they fear that the convertible issue will fall out-of-the-money during the conversion period. Of the 56 delayed-call firms included in the event study analysis, we identified 18 having underwritten calls and 38 having nonunderwritten calls. ${ }^{22}$ As is shown in Table 4, the coefficient estimate for UNDER in model 1 is negative and statistically significant. This finding is consistent with the results of Cowan, Nayar, and Singh (1992), and indicates that managers' uncertainty regarding stock prices over the conversion period is viewed negatively by investors. ${ }^{23}$

According to Kadapakkam and Tang (1996), larger calls may provide more negative information and may be associated with greater price pressure than calls of smaller issues. We add RELSIZE to our basic model to control for these effects. Similar to Kadapakkam and Tang (1996), model 2 in Table 4 reveals a negative relation between TWODAY and RELSIZE; however, in our model the size effect is not significant. Adding RELSIZE to the model also decreases the model's explanatory power, in that the adjusted $R_{2}$ for model 2 is 0.076 , compared to 0.095 for model 1 . Both of these values are comparable to those presented by Kadapakkam and Tang (1996).

To measure the effects of cash flow positions on abnormal returns, model 3

22. Underwriting data were collected from either the Investment Dealer's Digest Directory of Corporate Financing or the Wall Street Journal.

23. Kadapakkam and Tang (1996) and Hingorani et al. (1994) do not find the underwriting effect to be significant. 
includes DIVRAT. DIVRAT, as defined in Section 4, measures the magnitude of the cash flow disadvantage position. A ratio in excess of one identifies cash flow disadvantage firms, while a ratio less than one identifies cash flow advantage firms. The coefficient estimate for DIVRAT in model 3 is negative and significant, indicating that the larger the cash flow disadvantage to calling, the more negatively investors react to delayed call announcements. This result reveals that common shareholders view as negative firms' decisions to wake their "sleeping" preferred investors and, forthwith, pay dividends to them that are higher than were previously required (Ingersoll [1977a], Dunn and Eades [1989]). ${ }^{24}$ The inclusion of DIVRAT also increases the explanatory power of the model, relative to that of models 1 and 2.

The final specification presented in Table 4 adds EXTENT, which measures the extent to which the convertible preferred issue was in-the-money when it was called. Kadapakkam and Tang (1996) propose that the coefficient for EXTENT should be negative because firms that force conversion of deep-in-the-money securities "should fear severe trouble ahead." In contrast, Cowan, Nayar, and Singh (1992) propose a positive relationship because holders should have already converted on their own; therefore, the reason for the call is less likely to be negative information received by management. Similar to Kadapakkam and Tang (1996) and Hingorani et al. (1994), we find no relationship between abnormal returns and EXTENT. Therefore, in-the-moneyness does not appear to be an important determinant of price responses to convertible preferred stock call announcements.

In total, our cross-sectional analysis reveals that calls that are underwritten and that increase the relative dividend payment to convertible preferred holders are viewed more negatively by common stockholders. Additional specifications are reserved for Section 8 .

\section{Changes in Earnings Growth}

In this section, we investigate whether delayed calls of convertible preferred stock signal impending changes in the cash flow of calling firms. Similar to CEV, we utilize earnings before interest and taxes (EBIT) as a proxy for cash flows. ${ }^{25}$ We measured changes in earnings growth for our sample of firms relative to a matched sample of control firms from five years before to five years after the call announcements. Each firm in the call sample having a nonzero delay was assigned one match (control) firm based on the calling firm's three-digit SIC code and market value of equity at the end of the call announcement year. ${ }^{26}$ The "best" match was determined by comparing the ratio of the calling firm's market value of equity to

24. Both cash flow advantage and cash flow disadvantage firms have significantly negative abnormal returns. Therefore, some of the negative information signals associated with calls from a cash flow advantage position appear to exist for disadvantage firms as well.

25. Our results are similar when we define "earnings" as earnings per share.

26. There are nine firms for which two digit SIC codes were used. Similar results obtain when we match sample firms against industry averages rather than individual size-matched observations. 
the prospective matching firm's market value of equity. A ratio between 0.90 and 1.10 was deemed an acceptable match. ${ }^{27}$ Changes in EBIT growth were measured on an annual basis from years -5 to +5 relative to the call announcement year (year 0 ) using the method employed by CEV. Specifically, we estimate the following models (models 1 and 3 used by CEV):

$$
\begin{array}{ll}
\text { Model 1: } & P_{i t}=\varphi_{i}+\lambda_{i} D_{i t}+\varepsilon_{i t}, \\
\text { Model 2: } & \left(P_{i t}-P_{i t}^{c}\right)=\varphi_{i}+\lambda_{i} D_{i t}+\varepsilon_{i t}
\end{array}
$$

Earnings growth is calculated by subtracting the previous year's earnings from the current year's earnings and dividing by the previous year's earnings. Here $P_{i t}$ is the earnings growth rate for calling firm $i$ in year $t, D_{i t}$ is equal to zero for years prior to the call and one after the call, and $P_{i t}^{c}$ is the earnings growth rate for the match firm. Model 1 facilitates tests of pre-call earnings growth rates $(\varphi)$ and shifts in earnings growth rates $(\lambda)$. Model 2 provides a similar framework, with the coefficients representing deviations from industry norms. In both models, post-call earnings growth is measured, alternatively, from year 0 to year +3 , from year 0 to year +4 , and from year 0 to year +5 . Given the relatively small sizes of the subsamples, median values are presented in all cases. ${ }^{28}$

Panel A of Table 5 presents the earnings growth analysis as defined by model 1. We present results for the complete sample of firms, for the cash flow advantage partitions, and for the underwriting partitions. Across all three partitions, firms that called convertible preferred stock experienced significantly positive earnings growth during the five-year pre-call period. The median EBIT growth rate across all firms is 29.16 percent, with the largest growth experienced by cash flow advantage firms $(33.24 \%)$ and nonunderwritten firms (34.05\%). To explain the similarity between these two earnings growth rates, we conjecture that the underwriting decision is in part a function of the firm's performance prior to the call. As mentioned previously, managers typically choose to have their calls underwritten when they believe the securities may fall out-of-the-money during the conversion period. Assuming abnormally high pre-call earnings growth results in higher share prices (and, as a result, a lower likelihood that the securities will fall out-of-the-money within the 30- to 60-day conversion period), managers of firms that have recently experienced abnormally high earnings growth may be less likely to need to have their calls underwritten. In support of this contention, we find that 78 percent of the nonunderwritten calls are made by cash flow advantage firms. In other words, it seems likely that the tremendous pre-call earnings growth experienced by cash flow advantage firms translates into increasing share prices, which results in a decreased need for underwriting for these firms.

27. If more than one firm appeared to be equally well matched to the calling firm, the firm with the most years of available data and the most years of market value ratios between 0.90 and 1.10 was used.

28. The results using mean values and/or including only firms with positive option premia are comparable. 


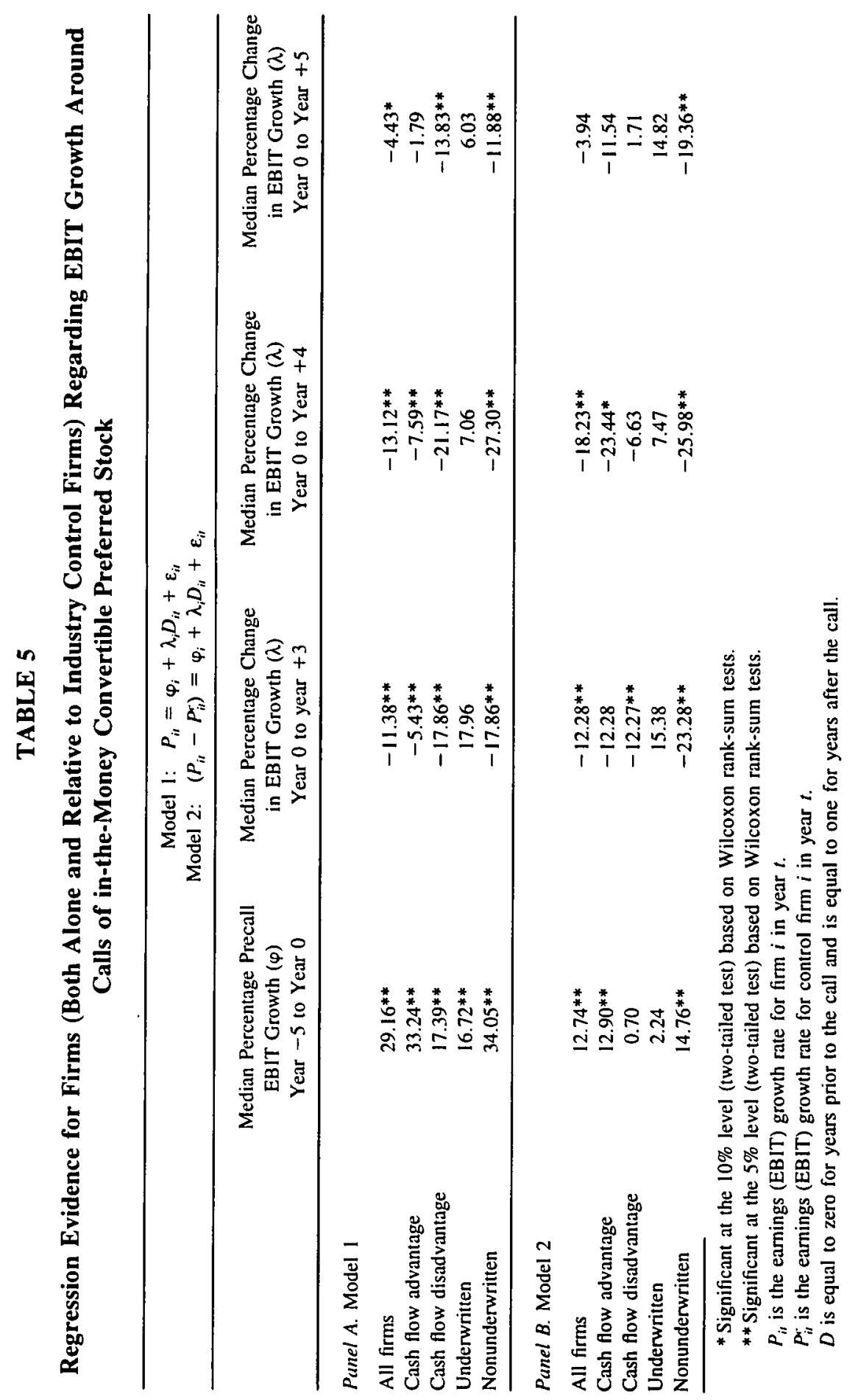


Panel A also illustrates that delayed calls of convertible preferred stock signal significant decreases in earnings growth. Across all firms, three-year post-call earnings growth (column 2) decreases by 11.38 points, representing a drop of almost 40 percent relative to the 29.16 percent pre-call growth rate. The four year postcall earnings growth (column 3 ) decrease of -13.12 points is also statistically significant. The downward shift in earnings growth is significant and negative for all subsets except firms that have their calls underwritten. The existence of significant decreases in earnings growth for disadvantage firms as well as advantage firms supports our conjecture that investors may react negatively to calls made by disadvantage firms both because of potential signaling elements and because such calls increase, unnecessarily, the dividends paid to convertible holders. In other words, the negative earnings signal adds to the cash flow disadvantage effect, which would also be consistent with the significantly negative estimate for DIVRAT in Table 4

When we measure earnings growth across five post-call years (column 4), the downward shift across all firms is still significant, but is less so than the shifts associated with three- and four-year earnings growth. Additionally, the five-year change in earnings growth for cash flow advantage firms, while negative, is not statistically significant. The decreased significance of the five-year change in earnings growth compared to the highly significant three- and four-year changes in earnings growth suggests that earnings-related signals are sent by delayed calls, but that the signals may be more informative about intermediate-term (i.e., three- to four-year) earnings trends.

In panel B of Table 5 we investigate earnings growth and changes in earnings growth relative to the matched sample of firms. Across all firms, pre-call earnings growth exceeds pre-call match firm earnings growth by 12.74 percent. In the postcall three-year period, however, the change in earnings growth relative to match firm earnings growth is -12.28 percent. Both estimates are statistically significant, indicating that firms that call convertible preferred stock experience abnormally positive (relative to comparable firms) earnings growth prior to the call and abnormally negative (relative to comparable firms) changes in earnings growth after the call. The inferences we draw from model 2 are not as strong as those from model 1; however, the matched sample results do generally support the firmspecific results that are reported in panel $A$. That is, delayed calls of convertible preferred stock do appear to signal significant changes in earnings growth.

\section{Additional Cross-Sectional Specifications and Sensitivity Tests}

\subsection{Earnings Growth}

If calls unambiguously signal expectations regarding future profitability, we would expect to observe a positive relationship between the shift in earnings growth from pre-call to post-call periods and price responses to call announcements. To 
test this proposition we added, individually, the earnings growth shift parameters ( $\lambda$ ) from eqs. (2) and (3) to the cross-sectional regression models presented in Table 4. The coefficient estimates for the earnings growth parameters were positive but not significant at conventional levels; the remaining coefficient estimates were comparable to those presented in Table 4 . Our conclusion is that the extent of the realized shift in earnings growth may not be perfectly incorporated into stock prices at the time of the call announcements.

\subsection{Price Pressure Effects}

Kadapakkam and Tang (1996) suggest that larger issues may be associated with relatively strong liquidity effects; as a result, RELSIZE should be positively related to post-announcement returns. They also propose that if the initial price effect is transitory, the announcement period returns should be negatively related to the post-announcement returns. To investigate these possibilities for our sample of firms, we regressed the cumulative abnormal return calculated from day +1 to day +50 relative to the call announcement on the two-day abnormal return and RELSIZE. ${ }^{29}$ In contrast to Kadappakam and Tang (1996), none of the coefficient estimates were significant at conventional levels. Our results, therefore, are more consistent with those of Mazzeo and Moore (1992), who find that common stock prices do not fully recover following calls of convertible preferred stock.

\subsection{Additional Signaling Effects}

Signaling models (e.g., Constantinides and Grundy [1987]) suggest that in-themoney cash flow advantage firms will delay calls in anticipation of voluntary conversion if managers have favorable inside information. These models show that longer delays should be associated with increasingly positive signals, which should correspond to increasingly positive pre-call stock price drifts. Similarly, longer delays should be associated with increasingly negative stock price responses when the calls eventually are announced (i.e., when the delay stops). Both of these predictions are supported by our data. We find a significant positive correlation between call delay length and the cumulative return measured between the date that the security was first in-the-money and the date the call was announced. We also find a significant negative correlation between call delay length and the two-day announcement period return, both in a univariate setting and when call delay length is included as an additional explanatory variable in Table 4. These results offer additional support for our contention that delayed calls reveal negative information concerning managers' expectations of future cash flows.

29. We define the post-announcement interval in a number of ways, including day +1 to day +25 , day +1 to day +75 , and day +1 to day +100 . Our results are not sensitive to these alternative specifications. 


\section{Summary and Concluding Remarks}

Numerous studies have examined the information content of in-the-money convertible preferred stock calls. The most important contribution of this paper is that information regarding call delays and cash flow positions is actively incorporated into the research design. In our first set of tests, we examine 71 in-the-money convertible preferred stock calls and find that 58 of the calls are delayed. These results are robust to numerous specifications of "delay" and cannot be explained by the cash flow position model of Asquith (1995). We then partition the sample into firms that delay calling and those that do not delay calling. For firms having delays, we find that the abnormal returns experienced on announcement are significantly negative; firms that call without delaying, however, do not experience significant price depreciation at announcement. In total, these results suggest that only delayed calls are likely to convey information to investors, a result that is both intuitively appealing and consistent with theoretical work regarding optimal call policy.

Based on these findings, we then investigate the potential determinants of share price reactions for firms with nonzero call delays. Our analysis reveals that price reactions to delayed call announcements are related both to the magnitude of firms' cash flow positions and to underwriting considerations. Specifically, share price reactions are increasingly negative the larger the cash flow (i.e., dividend) disadvantage to calling. Prices also respond more negatively when the calls are underwritten, due to the fact that the use of an underwriter signals managers' uncertainty regarding stock prices during the conversion period.

We also find that delayed calls of convertible preferred stock are associated with significant decreases in earnings growth. Our results hold for both cash flow advantage firms and cash flow disadvantage firms. Our findings for disadvantage firms suggest that the increasingly negative share price response for these firms is due both to the inherent cash flow disadvantage associated with the forced conversion as well as to the presence of a significantly negative earnings signal. We leave further refinements and additional investigation to future researchers. At a minimum, subsequent research should adequately control for call delays and cash flow positions in investigating the information content of convertible preferred stock calls.

\section{REFERENCES}

Acharya, S., and P. Handa. 1991. "Early Calls of Convertible Debt: Theory and Empirical Evidence." Working paper, New York University.

Asquith, P. 1995. “Convertible Bonds Are Not Called Late." Journal of Finance 50:1275-1289.

Asquith, P., and D. Mullins. 1991. "Convertible Debt: Corporate Call Policy and Voluntary Conversion." Journal of Finance 46:1273-1290.

Brennan, M. J., and E. S. Schwartz. 1997. "Convertible Bonds: Valuation and Optimal Strategies for Calls and Conversion." Journal of Finance 32:1699-1715.

Brigham, E. 1966. "An Analysis of Convertible Debentures: Theory and Some Empirical Evidence." Journal of Finance 21:35-54. 


\section{CONVERTIBLE PREFERRED STOCK CALLS}

Byrd, A., S. Mann, W. Moore, and P. Ramanlal. 1997. "Rational Timing of Calls of Convertible Preferred Stocks." Unpublished manuscript.

Byrd, A., and W. Moore. 1996. "On the Information Content of Calls of Convertible Securities." Journal of Business 69:89-101.

Campbell C., L. Ederington, and P. Vankudre. 1991. "Tax Shields, Sample-Selection Bias, and the Information Content of Conversion-Forcing Bond Calls." Journal of Finance 46:1291-1324.

Constantinides, G., and B. Grundy. 1987. "Call and Conversion of Convertible Corporate Bonds: Theory and Evidence." Working paper, Graduate School of Business, University of Chicago.

Cowan, A. R., N. Nayar, and A. K. Singh. 1992. "Underwriting Calls of Convertible Securities." Journal of Financial Economics 31:269-278.

Cowan, A. R., N. Nayar, and A. K. Singh. 1993. "Calls of Out-of-the-Money Convertible Bonds." Financial Management 22:106-116.

Dunn, K., and K. Eades. 1989. "Voluntary Conversion of Convertible Securities and the Optimal Call Strategy." Journal of Financial Economics 23:273-302.

Harris, M., and A. Raviv. 1985. "A Sequential Signaling Model of Convertible Debt Call Policy." Journal of Finance 40:1263-1281.

Hingorani, A., A. Makhija, and K. Shastri. 1994. "The Impact of Calls of Preferred Stock on Common Shareholder Wealth." Journal of Banking and Finance 18:1095-1112.

Ingersoll, J. E. 1977a. "A Contingent Claims Valuation of Convertible Securities." Journal of Financial Economics 4:289-322.

Ingersoll, J. E. 1977b. "An Examination of Corporate Call Policy on Convertible Securities." Journal of Finance 32:463-478.

Jaffe, D., and A. Shleifer. 1990. "Costs of Financial Distress, Delayed Calls of Convertible Bonds, and the Role of Investment Banks." Journal of Business 63:S107-S123.

Kadapakkam, P., and A. Tang. 1996. "Stock Reaction to Dividend Savings of Convertible Preferred Calls: Free Cash Flow or Price Pressure Effects?" Journal of Banking and Finance 20:17591774.

Mais, E., W. Moore, and R. Rogers. 1989. "A Reexamination of Shareholder Wealth Effects of Calls of Convertible Preferred Stock." Journal of Finance 44:1401-1410.

Mazzeo, M., and W. Moore. 1992. "Liquidity Costs and Stock Price Response to Convertible Security Calls." Journal of Business 65:353-369.

Mikkelson, W. 1981. "Convertible Calls and Security Returns." Journal of Financial Economics 9: 237-264.

Mikkelson, W. 1985. "Convertible Calls and Stock Price Declines." Financial Analysts Journal 41: 63-69.

Mikkelson, W., and M. Partch. 1988. "Withdrawn Security Offerings." Journal of Financial and Quantitative Analysis 23:119-133.

Ofer, A., and A. Natarajan. 1987. "Convertible Call Policies: An Empirical Analysis of an InformationSignaling Hypothesis." Journal of Financial Economics 19:91-108.

Scholes. M., and J. Williams. 1977. "Estimating Betas from Nonsynchronous Data." Journal of Financial Economics 5:309-327.

Shastri, K., and K. Shastri. 1996. "The Information Content of Calls of Convertible Preferreds: The Evidence from Earnings Forecasts." Journal of Accounting, Auditing \& Finance 11:607-621.

Tang, A., P. Kadapakkam, and R. Singer. 1994. "The Valuation Effects of Out-of-the-Money Calls of Convertible Securities." Journal of Financial Research 17:481-493. 